\title{
EDITORIAL \\ Operating outside the operating room: how do we measure the implications?
}

\author{
Vibhor Krishna, MD, ScM, ${ }^{1,2}$ and Mojgan Hodaie, MD ${ }^{3-5}$ \\ ${ }^{1}$ Center for Neuromodulation, Department of Neurosurgery; ' ${ }^{2}$ epartment of Neuroscience, Ohio State University, Columbus, \\ Ohio; ${ }^{3}$ Division of Neurosurgery, Department of Surgery; ${ }^{5}$ nstitute of Medical Science, Faculty of Medicine, University of \\ Toronto; and ${ }^{4}$ Division of Brain Imaging, Behaviour Systems Neuroscience, Toronto Western Research Institute, Toronto, \\ Ontario, Canada
}

$\mathrm{D}$ EEP brain stimulation (DBS) is an established treatment for advanced Parkinson's disease, refractory essential tremor, and dystonia. ${ }^{6}$ Several investigations are underway to explore its novel application for psychiatric and other neurological disorders. The safety profile of this procedure is well established. With respect to associated complications, the current literature points to risks such as infection (1\%-2\%), hematoma (2\%-4\%), and long-term hardware failure $(5 \%-7 \%){ }^{5}$

Deep brain stimulation is a unique surgical procedure. It is minimally invasive, yet involves introducing a significant number of probes and devices deep into the brain. Although the technique has evolved over the years, it commonly involves neurophysiological exploration of the brain targets ${ }^{4}$ to gather maximum information and ensure accurate target selection. Intraoperative neurophysiological evaluation requires the patient to be awake. ${ }^{11}$ Some patients are extremely hesitant about awake surgery. Magnetic resonance imaging-guided DBS implantation is an important alternative for these patients, since it allows the procedure to be done under general anesthesia and relies on MRI to guide electrode placement. Martin and colleagues have been pioneers in this field and have published their results as regards procedural efficacy and accuracy. ${ }^{8,9}$ In their article, Martin et al. ${ }^{7}$ describe their 10-year experience with hardware-related infections in a large case series of 164 DBS procedures performed in the intraoperative MRI suite, outside the operating theater, without the same airflow and filtration standards. They conclude that similar rates of infection can be achieved in both environments.

There are important messages to be derived from their study. The authors expended considerable effort in creating a sterile environment in the MRI suite (thorough cleaning of the MRI room, surgical attire for personnel entering the room, and avoidance of direct airflow to the surgical field), using an aseptic technique (operating room team for the surgery, wound cleaning, and extensive draping), and preparing the patient (preoperative screening for bacterial colonization and perioperative antibiotic administration). They collected data up to 6 months after surgery to increase the likelihood of capturing indolent, deep incisional infections, given the presence of prosthetics. Factors such as procedure duration, most common pathogens, and patient age were also studied. With the data provided, it is reasonable to conclude that a center with a significant wealth of experience in DBS surgery can perform procedures in the MRI suite with a very reasonable rate of infection.

There are several questions worth exploring, however. The central question of their study is whether an operating area that has not been designated or constructed with the same standards as an operating theater poses a greater risk of surgical site infection. This is a very difficult question to study. Should we presume that if there is a greater risk of infection, then the pathogens will still be commensal skin microorganisms, the most commonly seen sources, ${ }^{3,10}$ or will more unusual infectious organisms be encountered? We must also take into account that these cases are technically rigorous and involve the manipulation of multiple pieces of hardware that move through the sterile field, and that there is a significant learning curve before a surgeon becomes facile with DBS procedures. ${ }^{1}$ How do these issues affect the infection rate? Importantly, the authors' low infection rate may not be so easily translated into similar rates for institutions where the experience is more recent or the cases less frequent. Finally the applicability to emerging DBS indications-for example, 
epilepsy-with inherently higher rates of infection due to patient-related factors (poor nutritional status, risk of other systemic infections) remains unresolved. ${ }^{2}$

In an era of increasing surgical complexities and cases transported from the surgical theater to the imaging suite, the potential implications must be studied by gathering a large amount of multicenter data for a more profound conclusion.

http://thejns.org/doi/abs/10.3171/2015.9.JNS151699

\section{References}

1. Falowski SM, Ooi YC, Bakay RA: Long-term evaluation of changes in operative technique and hardware-related complications with deep brain stimulation. Neuromodulation [epub ahead of print], 2015

2. Fisher R, Salanova V, Witt T, Worth R, Henry T, Gross R, et al: Electrical stimulation of the anterior nucleus of thalamus for treatment of refractory epilepsy. Epilepsia 51:899-908, 2010

3. Hamani C, Lozano AM: Hardware-related complications of deep brain stimulation: a review of the published literature. Stereotact Funct Neurosurg 84:248-251, 2006

4. Hutchison WD, Allan RJ, Opitz H, Levy R, Dostrovsky JO, Lang AE, et al: Neurophysiological identification of the subthalamic nucleus in surgery for Parkinson's disease. Ann Neurol 44:622-628, 1998

5. Kleiner-Fisman G, Herzog J, Fisman DN, Tamma F, Lyons KE, Pahwa R, et al: Subthalamic nucleus deep brain stimulation: summary and meta-analysis of outcomes. Mov Disord 21 (Suppl 14):S290-S304, 2006

6. Lozano AM, Lipsman N: Probing and regulating dysfunctional circuits using deep brain stimulation. Neuron 77:406-424, 2013

7. Martin AJ, Larson PS, Ziman N, Levesque N, Volz M, Ostrem JL, et al: Deep brain stimulator implantation in a diagnostic MRI suite: infection history over a 10 -year period. J Neurosurg [epub ahead of print March 25, 2016. DOI: 10.3171/2015.7.JNS15750]

8. Ostrem JL, Galifianakis NB, Markun LC, Grace JK, Martin AJ, Starr PA, et al: Clinical outcomes of PD patients having bilateral STN DBS using high-field interventional MR-imaging for lead placement. Clin Neurol Neurosurg 115:708712,2013
9. Starr PA, Martin AJ, Ostrem JL, Talke P, Levesque N, Larson PS: Subthalamic nucleus deep brain stimulator placement using high-field interventional magnetic resonance imaging and a skull-mounted aiming device: technique and application accuracy. J Neurosurg 112:479-490, 2010

10. Tolleson C, Stroh J, Ehrenfeld J, Neimat J, Konrad P, Phibbs F: The factors involved in deep brain stimulation infection: a large case series. Stereotact Funct Neurosurg 92:227-233, 2014

11. Venkatraghavan L, Luciano M, Manninen P: Review article: anesthetic management of patients undergoing deep brain stimulator insertion. Anesthes Analg 110:1138-1145, 2010

\section{Disclosures}

The authors report no conflict of interest.

\section{Response}

\section{Alastair J. Martin, PhD, ${ }^{1}$ Paul S. Larson, MD, ${ }^{2}$ and Philip A. Starr, MD, PhD²}

Departments of ${ }^{1}$ Radiology and Biomedical Imaging, ${ }^{2}$ Neurological Surgery, and ${ }^{3}$ Neurology, University of California, San Francisco, California

We thank Drs. Krishna and Hodaie for their insightful editorial comments. We agree that there is a subset of DBS patients who are more appropriate for a surgical approach that does not require them to be awake. We also agree that other centers should approach the issue of sterility with caution and that conclusions cannot presently be made regarding the applicability of our findings to other institutions. Their comments regarding the potential for alternate pathogens are interesting, but our study provided no evidence to either support or refute this possibility. We believe that the critical conclusion from our study is that it is possible to perform MRI-guided DBS implantations in a conventional MRI suite and to achieve a low incidence of infection. Other centers adopting this approach would be prudent to adhere to sterile practices as outlined in our article and to carefully monitor for infections, particularly in the early phases of program implementation. 